Journal of Education and Vocational Research

Vol. 3, No. 6, pp. 178-182, June 2012 (ISSN 2221-2590)

\title{
The Role of Education within a Knowledge Based Society: Teachers' Perception on how e- Learning Systems can be integrated in Classroom Activities
}

\author{
Raluca Cristina Eftimie \\ Doctoral Studies Institute, Bucharest Academy of Economic Studies, Romania \\ raluca.cristina.eftimie@gmail.com
}

\begin{abstract}
The development of the interactive, collaborative and dynamic e-learning methods is considered the primary mode of evolution of the Romanian and international educational systems. Most of the studies have revealed the widespread benefits of these technologies and exemplifying their applicability and their evolution within the education systems. However, few studies clearly identify the role that e-learning platforms have in the improvement of teaching - learning and how these technologies can be integrated into the classroom. This article proposes a new approach related to the integration of these systems while providing educational acts, starting by identifying and understanding the perceptions that teachers have regarding this type of innovative technology, explaining and interpreting the results of a qualitative research conducted within Romanian educational market. Teacher's perception on the role of e-learning education is interpreted as a factor, which influences the quality of the use and the integration of these technologies in the Romanian educational environment, reaffirming the need for a coherent implementation of these instruments at a specific school level but also at general educational environment integration.
\end{abstract}

Key Words: Education, e-learning, innovation, perception, integration

\section{Introduction}

Within the context of the contemporary society, education is becoming a continuous activity, which focuses on developing the intellectual capacities of the individual, an activity generated and pronounced throughout life by his desire for knowledge and by the practical experiences covered by years. The educational process is seen as a continuous and evolving one, according to age and the training level of the individual. According to the European Commission, EU states would develop by the end of 2010 "the most Competitive and dynamic society based on knowledge from the entire world" (European Commission, 2004). Directions are maintained on long-term. Knowledge-based economy is a reality of the contemporary society and education is considered the primary mobile of its evolution. In the new knowledge economy, human capital is the main factor generating the economic and social progress. The development of the modern society is becoming increasingly linked to the quality of the education system. Knowledge is seen as a complex transfer, assimilation, interpretation and dissemination of information. All of this starts from the individual's intellectual capacity, able to provide value added to the information received through an internal process of interpretation of the meaning of objects and events. This process is called learning (Rowley, in Steyn, 2004). Learning leads to knowledge, which may be tacit (embedded in the minds of individuals) or explicit (communicated formally or informally). The last stage of this process is the feedback obtained, which is the premise of knowledge creation. "O'Connell (1999), Mattensson (2000) and Shariq (1998) consider knowledge as a result of the interpretation of information by individuals who in this case creates and stores knowledge" (O'Connel, Matteson and Shariq, in Steyn, 2004). Therefore education becomes the activity by which individuals gather the necessary information to store and interpret them in order to generate the knowledge to other individuals. The role of education is not just the mere transmission of information but also providing the necessary specific dissemination through socialization process. The individual education can provide a superior adaptation to the environment to enhance owns welfare and that of the entire community. Social transformations caused by the emergence, development and the new directions of the knowledge-based economy led to many changes within the education system. Although the general structure of the educational cycles has remained constant, the aim of identifying the best choice of schooling and assessment lead to progressive changes in secondary education cycles and especially in higher education. Most of them aim to introduce IT technology in education as the main agent of transmission, dissemination and evaluation of the 
taught information and their level of assimilation. The requirements of the new knowledge based society do not resume only to the enhancing of the role of formal education, but also to the increase of the overall quality of educational services and also to the development of the informal education by recognizing the widespread importance of lifelong learning. The limits of these two types of educational activities are undetectable, thus ensuring continuity of formal education through informal education. The specific aspects of the educational processes change, moving from a one -way process to bi-way process. The role of students' feedback increases, emphasizing the importance of the interactive, proactive and anticipatory teaching. Developing elearning environments is therefore a precondition for an effective educational environment and in accordance with the requirements of the knowledge-based society.

\section{Literature Review}

Since ancient times education was defined as "the art of forming good habits" (Platon, 1994) or "object of public oversight" (Aristotel, 2001). John Locke presents education as "an interpersonal relationship of surveillance and intervention that is established between" tutor "(teacher) and child (Calin, 2001). Over time the perception on education changes and a many of the ancient approaches evolved. Emile Durkheim believed that "education is a methodical socialization of the young Education"(Durkheim, 2005). Within contemporary knowledge - based society, different field activities are strongly connected and related to education and educational system. The increasing demand on the labor market and the continuous outline of the importance of human capital for achieving economic progress led to the development of new techniques and technologies that enable the provision of quality educational acts. Through these students, regardless the initial training level, are able to learn in an active way of receiving and disseminating information and experiences. The need to develop a collaborative learning system contributed to the emergence and widespread use of virtual environments as a support for the educational socialization acts and for an interactive training. The process of creation and dissemination of knowledge, as the main premise for the existence of an education based society, is considered strongly dependent of the capacity of the individual to assimilate, interpret and disseminate information and of teacher's ability to transmit and explain the necessary information. This new approach changes the role of education within the social system, giving it a bidirectional development strategy by considering both teachers and students' necessities and motivations. Starting from this orientation, educational technologies and techniques suffered many changes in the last years, gaining more and more attention within educational environment.

Educational innovation requires "flexibility, independence, orientation student / student, learning and technology", confirms Steel, J. and A. Hudson in "Educational Technology in Learning and Teaching: The Perceptions and Experiences of Teaching Staff" revealing the importance of technology in producing positive changes within educational environment (Steel, Hudson, 2001). In the educational process, technology is considered a tool to improve teaching efficiency and even more. Although the initial term of technology education refers only to the use of technological means in the educational process, it has become a primary resource, which generates group and individual school performance. Vaideanu defines the concept of educational technology as "all methods, means and ways of organizing learning, from which the teacher selects the necessary elements of design, conduct and evaluation of an activity or a didactic system or of an extracurricular activity based on the teaching objectives of content and learning situations " (Cojocaru, 2010). The effectiveness of the educational technology for the improvement of school performance is assessed in terms of assigning a marketing orientation, an orientation towards pupil / student, the main consumers of the educational acts. By increasing the interaction student - teacher and by introducing elements of interactivity in the classroom, the use of educational technology is a factor of progress of the educational environment thus meeting the requirements of the knowledge society.XXI century education involves the identification and spread of three essential elements: professionalism and quality of the lifelong learning, creating and developing knowledge and its dissemination. The base of all of these three elements is innovation, and especially ITC innovation (Weert, 2006). Although originally developed in response to the need of companies for a quick and effective training of the employees, e-learning platforms have become useful to any field of activity, distance learning being considered a complementary solution to traditional education systems. The first attempts to introduce technologies in the educational environment occur in the U.S. mid-twentieth century. It highlights the experimental attempts to use computer to teach primary school children in Palo 
Alto, California to read or to teach elementary mathematics. Based on these experiments was created later Gifted Youth Education Program (www.wikipedia.org).

Virtual learning systems supported by recent computer learning, often tried to reproduce authoritarian learning systems where the role of virtual learning modality was considered the transfer of knowledge, opposed to the later methods based on computer-assisted collaborative learning, which encouraged the development of knowledge sharing. In modern society many technologies can be, and are used in e learning, from blogs to collaborative software, electronic portfolio and virtual classrooms. In most cases when using e learning, or rather, when using new technologies in education, combinations of these techniques are used. There is also an increased use of virtual classrooms (online presentations broadcast live) as an online learning platform for a diverse range of providers of educational services. In addition to virtual environment classes, social networks have become an important part of e learning. Social networks have been used to promote online learning community around various themes such as preparation for testing or learning a foreign language. Although these schools did not respond to trends, most teachers rejected traditional social networking in education, unless the communication is between them and their own colleagues. According to Inglis, the essential factor of the evolution is technology, this being the response for the requirements of the contemporary for providing flexible systems within temporal and spatial relations. In literature, e-learning technology is considered the creator and developer of global virtual communications, complex environments in which schools are central - strategic in creating and disseminating knowledge (Inglis, Ling \& Joosten, 2002). Trigwell, Prosser and Waterhouse discuss on the relation between teachers' perceptions on learning and teaching and those influence on the quality of the students' learning outcomes (Trigwell, Prosser \& Waterhouse, 1999). In their opinion "teachers who view learning as a conceptual change are more likely to view teaching as facilitating conceptual change and there wise are more likely to use student centered teaching approaches" (Prosser \& Trigwell, 1999). Their study can be easily applied to the case of innovative technology.

Fig. 1: Teacher - student perceptions and the quality of learning outcomes

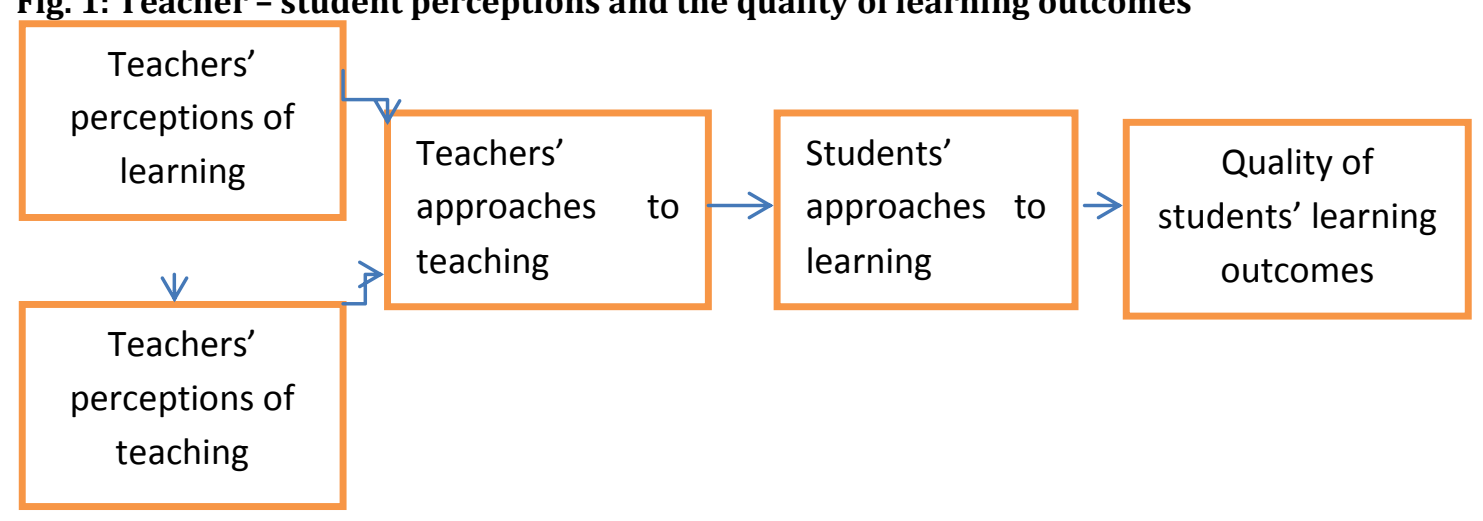

Fig. 1 Teacher - student perceptions and the quality of learning outcomes. (Adapted from Cope, Ward, "Integrating learning technologies into classroom: The importance of teachers' perceptions", Educational Technology \& Society 5(1) 2002). Cope and Ward lead a qualitative study concerning teachers' perceptions on learning technologies according to some components related to the way of integrating these technologies into classroom processes. According to their findings, "learning technologies were perceived as technology which enhanced learning" (Cope \& Ward, 2002). "What" component referred to the content and to the learning aspects of the technology, while "how" component investigated the impact of the technology on students' learning, and on its utility? The outcomes of the study reflected a positive perception on the use of the technology and on its utility. Introducing e-learning platforms in the classroom is the current level of evolution. Therefore, considering them as essential factors to stimulate educational progress is a prerequisite need for the development of the overall educational environment. 


\section{Methodology}

The present article aims to identify the role that e-learning education is held in the local educational system and the elements that give this role. Starting from the typology, responsibility and decision capacity of the agents involved in the educational environment, the present study considered the opinion that teachers have about the way of integration and the role of these innovative technologies in the classroom. The study was conducted on a sample of 20 teachers from Romanian high schools. Teachers were recruited through a questionnaire that sought to identify age in education (experience), the subject they teach and of course other indicators such as age and sex. The target group included teachers with experience ranging from 10 to 20 years, and aged between 35 and 45. The taught discipline was selected completely random, the selected teachers being specialized in areas such as geography, history, physics, and biology. The qualitative research carried out revealed the perception of teachers about the role that e-learning systems have in the classroom but also how they projected the integration of these technologies in teaching and learning processes.

\section{Results}

The emergence and development of Internet and Web technologies according to the increasing social demand for education prompted the emergence and evolution of e learning as a support for continuing education and a tool for teaching - learning processes. The impact of the Internet gradually changed the key aspects of the educational environment through significant transformation of school curricula, introduction of new study materials or new techniques and teaching methods. The continuous development of the educational technology and the constant increase of their importance for boosting the teaching - learning is prerequisite for widespread integration of e-learning systems in the Romanian educational environment. The real need to use ITC in the Romanian educational system, although recognized in any policy and approved by authorities in the field, remains a goal difficult to implement in practice. The study conducted tries to identify the ways in which these technologies could be actively integrated in classes, from the perspective of the main users teachers.

The role of e-learning systems within Romanian classrooms: Asked to identify the role of e-learning platforms in teaching - learning processes, starting from the benefits and disadvantages that these educational tools present, most teachers in the sample felt that they serve the educational acts by stimulating the development of interactivity and cooperation between students and between teacher and students. Contributing to increasing level of students' attention, the lessons taught in e-learning system are much easier to teach, the technologies used also facilitating the assimilation and proper understanding of the information provided. "Using e-learning platforms in classroom would make learning more efficient for students," said one of the teachers included in the sample under investigation. The efficiency of the teaching - learning processes is often perceived by teachers not only through their students' academic results but also by the ease with which they assimilate and interpret information, thus contributing to the creation and subsequent dissemination of knowledge. Using audio and video elements, animation working schemes and other multimedia technologies are some of the main advantages of e - learning platforms identified by teachers who took part in the study. The importance of these elements in increasing the efficiency of teaching and learning processes is acknowledged and recognized by most teachers, starting from the need to provide interactivity as key motivator for students.

Ways to integrate e-learning platforms in the classroom: Although considered as educational tools with a significant contribution in the efficiency of the learning process, e-learning platforms are difficult to assimilate technologies within the educational environment in the moment of classroom integration. Although excited about the possibility of using these technologies and the advantages, which they present, most teachers included in the present study recognized that they did not manage to actively integrate these tools within the teaching - learning processes held in class. "I think the existence of an adequate infrastructure in school would help me to integrate these technologies into the lessons taught to students," said one of the teachers in the target group of the study. Although many of the schools surveyed have elearning laboratories, their small number and antiquated infrastructure make quite impossible the frequent use of those, which makes their real integration within curricula impossible."I am frequently using e-learning platforms in the classroom especially to check students' knowledge but also to present them in a dynamic 
way the geographical phenomena on various topics," said one of the teachers in the interview in depth supported. Developer of e-learning systems for the Romanian secondary education, he identifies the main problem for which innovative technologies are not sufficient or well integrated in the educational environment: "As long as the teacher does not understand or try to understand how to use and the real results that these technologies can bring in today education, he will not be able to achieve their effective integration in the lessons taught. Integration does not refer to a simple, sporadic use of these platforms, but to the transformation of the entire class in an interactive environment, by a collaborative and dynamic teaching - learning process". Teachers' perception on these platforms, on the usefulness and ease of their use therefore remains the main factor of influence in predicting the role that these innovative technologies can hold within Romanian and any other educational system.

\section{Conclusion}

Starting from the necessity of using and integrating innovative technologies in the Romanian educational environment, the present study revealed through a qualitative research, teachers' perceptions about the role and how to integrate e-learning technologies into classroom current activity. Recognized as tools that could bring a significant contribution to the process of improving students' academic results, e-learning platforms are rarely used in classes and even little integrated within teaching - learning processes. The causes are different starting from the lack of infrastructure and its poor quality and getting to the inability to clearly identify a method of integration in class. The random use of these systems to explain some phenomena from the different subjects taught is not a method to integrate them and neither to increase the efficiency of the educational services. The qualitative research conducted is first step of a study that aims to identify the perception of teachers on the use of e-learning technology and its influence on its place in the Romanian educational environment and beyond. The results of in-depth interviews conducted with a small sample of teachers will be further tested through quantitative research conducted on a representative sample of teachers of Romanian secondary education.

\section{References}

Aristotel. (2001). Politica, Bucuresti, Antet Publishing House

Calin, M. (2001). Filo Sofia Educaţiei, Bucureşti, Aramis Publishing House.

Cojocaru, V. (2010).Teoriasime todologiatransferuluiinovational in invatamantul superior, PhD. Thesis

Cope, C. \& Ward, P. (2002). Integrating learning technology into classrooms: The importance of teachers' perceptions. Educational Technology \& Society, 5(1), 9.

Durkheim, E. (2005). Education etsociologie, Paris, PUF

European Commission. (2004). European Commission Report, 5

Http: //www.wikipedia.org/ accesat la 20. 03.2012

Inglis, A., Ling, P. \& Joosten, V. (2002). Delivering digitally, London: Kogan Page

Kotler, P. H. \& Keller, K. (2008). Management Marketingului, Bucureşti, Ed Teora

Steyn, G. M. (2004). Harnessing the power of knowledge în higher Education. International Journal of Education, 204(2).

Platon, G. (1994). Republica, Didactic and pedagogical Publishing House, Bucharest

Prosser, M. \& Trigwell, K. (1999). Understanding learning and teaching: the experience in higher education, Philadelphia, PA: Society for Research into Higher Education \& Open University Press.

Steel, J. \& Hudson, A. (2001). Educational Technology în Learning and Teaching: The Perceptions and Experiences of Teaching Staff. Innovations in Education and Teaching International, 38(2), 103-137.

Trigwell, K., Prosser, M. \& Waterhouse, F. (1999). Relations between teachers' approaches to teaching and students' approaches to learning. Higher Education, 37, 57-70.

Van-Weert, T. J. (2006). Education of the 21-st century: New professionalism in lifelong learning, knowledge development and knowledge sharing. IFIP Conference, Imagining the future for ICT and education, Aalesund, 217. 